\title{
The history of attention deficit hyperactivity disorder
}

\author{
Klaus W. Lange - Susanne Reichl - Katharina M. Lange • \\ Lara Tucha $\cdot$ Oliver Tucha
}

Received: 25 July 2010/ Accepted: 29 October 2010/Published online: 30 November 2010

(C) The Author(s) 2010. This article is published with open access at Springerlink.com

\begin{abstract}
The contemporary concept of attention deficit hyperactivity disorder (ADHD) as defined in the DSM-IVTR (American Psychiatric Association 2000) is relatively new. Excessive hyperactive, inattentive, and impulsive children have been described in the literature since the nineteenth century. Some of the early depictions and etiological theories of hyperactivity were similar to current descriptions of ADHD. Detailed studies of the behavior of hyperactive children and increasing knowledge of brain function have changed the concepts of the fundamental behavioral and neuropathological deficits underlying the disorder. This article presents an overview of the conceptual history of modern-day ADHD.
\end{abstract}

Keywords ADHD - Attention deficit · Hyperactivity · History

\section{Introduction}

The characteristic features of children and adolescents with attention deficit hyperactivity disorder (ADHD) are excessive motor activity, inattention, and impulsiveness.

K. W. Lange - S. Reichl - K. M. Lange

Department of Biological and Abnormal Psychology,

University of Regensburg, Regensburg, Germany

L. Tucha $\cdot$ O. Tucha

Department of Clinical and Developmental Neuropsychology,

University of Groningen, Groningen, The Netherlands

K. W. Lange $(\bowtie)$

Institute of Experimental Psychology,

University of Regensburg, 93040 Regensburg, Germany

e-mail: Klaus.Lange@psychologie.uni-regensburg.de
The contemporary concept of ADHD as defined in the DSM-IV-TR (American Psychiatric Association 2000) is relatively new. However, an analysis of historical literature suggests that children presenting with symptoms of inattention, hyperactivity, and impulsivity have previously been described by several authors during the last 200 years. The clinical characterizations, underlying concepts, and nomenclature of the described dysfunctions have changed over the time. Many of the historical descriptions are, however, consistent with the modern diagnostic criteria for ADHD. The present article gives an overview of the conceptual history of modern-day ADHD.

The incapacity of attending with a necessary degree of constancy to any one object (Sir Alexander Crichton, 1763-1856)

The first example of a disorder that appears to be similar to ADHD was given by Sir Alexander Crichton in 1798 . Crichton was a Scottish physician who was born in Edinburgh in 1763. In 1785, he received his M.D. from the University of Leiden, The Netherlands (Palmer and Finger 2001; Tansey 1984). He then decided "to undertake a European medical tour" (Tansey 1984, p. 243) and practiced in hospitals in Paris, Stuttgart and Vienna (Tansey 1984). In his clinical practice, Crichton observed many cases of insanity and became increasingly interested in mental illness (Palmer and Finger 2001). In 1798, he published "An inquiry into the nature and origin of mental derangement: comprehending a concise system of the physiology and pathology of the human mind and a history of the passions and their effects". In this work of three books, he demonstrated observations of clinical cases of mental illness (Palmer and Finger 2001). Up until the end 
of the eighteenth century, when Crichton published his inquiry, it was uncommon to focus on mental issues from a physiological or medical perspective (Palmer and Finger 2001). Crichton mentioned that at the time there were only two other authors who had "written fully on the subject of Mental Diseases" (Crichton 1798, pp. ii-iii, cited by Palmer and Finger 2001).

The second chapter of book II "On Attention and its Diseases" is of special interest to the present subject. Crichton begins this chapter with a definition of attention: "When any object of external sense, or of thought, occupies the mind in such a degree that a person does not receive a clear perception from any other one, he is said to attend to it" (Crichton 1798, reprint p. 200). Crichton emphasizes that the intensity of healthy attention varies within a normal range both between individuals and even within a person at different times (Crichton 1798). A distraction of attention does not necessarily have to be pathological, e.g. mental stimuli, volition, or education can have a great impact on healthy attention (Crichton 1798). Crichton distinguishes two possibilities of abnormal inattention as the oppositional poles of pathologically increased or decreased "sensibility of the nerves" (Crichton 1798):

The morbid alterations to which attention is subject, may all be reduced under the two following heads:

First. The incapacity of attending with a necessary degree of constancy to any one object.

Second. A total suspension of its effects on the brain. The incapacity of attending with a necessary degree of constancy to any one object, almost always arises from an unnatural or morbid sensibility of the nerves, by which means this faculty is incessantly withdrawn from one impression to another. It may be either born with a person, or it may be the effect of accidental diseases.

When born with a person it becomes evident at a very early period of life, and has a very bad effect, inasmuch as it renders him incapable of attending with constancy to any one object of education. But it seldom is in so great a degree as totally to impede all instruction; and what is very fortunate, it is generally diminished with age. (Crichton, 1798, reprint p. 203)

In this short description of the first alteration of attention, Crichton gives several indications that he was depicting the same disorder as defined in the current DSM-IV-TR criteria of ADHD. His characterization of the disorder as "the incapacity of attending with a necessary degree of constancy to any one object" is consistent with the second symptom of criterion A1, Inattention: the "difficulty sustaining attention in tasks or play activities" (American Psychiatric Association 2000). Crichton further describes that "this faculty is incessantly withdrawn from one impression to another", which fits with a second DSMIV-TR symptom of inattention, namely the circumstance that the patient "is often easily distracted by extraneous stimuli" (American Psychiatric Association 2000). The American Psychiatric Association (2000) furthermore determines that for the diagnosis of ADHD, the symptoms have to be present before the age of seven. Crichton also reports that the disorder can be "born with a person" and "when born with a person it becomes evident at a very early period of life" (Crichton 1798). The proximate conclusion that "it renders him incapable of attending with constancy to any one object of education" (Crichton 1798) suggests that Crichton observed school difficulties in these children, which are commonly seen in children with ADHD. Crichton states that the disorder "generally diminished with age" (Crichton 1798). The notion that ADHD is a disorder of childhood and affected children "grow out" of ADHD during puberty (Okie 2006) was common until the 1990s (Barkley 2006a). Recent studies have shown that about $50 \%$ of children diagnosed with ADHD retain symptoms of ADHD into adulthood (Okie 2006; Arolt 2008).

According to Crichton, the incapacity of attending, if not innate, can also be caused by nervous disorders. This notion was later rediscovered in the concepts of minimal brain damage or dysfunction.

In this disease of attention, if it can with propriety be called so, every impression seems to agitate the person, and gives him or her an unnatural degree of mental restlessness. People walking up and down the room, a slight noise in the same, the moving a table, the shutting a door suddenly, a slight excess of heat or of cold, too much light, or too little light, all destroy constant attention in such patients, inasmuch as it is easily excited by every impression. The barking of dogs, an ill-tuned organ, or the scolding of women, are sufficient to distract patients of this description to such a degree, as almost approaches to the nature of delirium. It gives them vertigo, and headache, and often excites such a degree of anger as borders on insanity. When people are affected in this manner, which they very frequently are, they have a particular name for the state of their nerves, which is expressive enough of their feelings. They say they have the fidgets. (Crichton, 1798, reprint p. 203)

By citing these examples of his patients' behaviors, Crichton depicts a great distractibility by extraneous and even slight stimuli, a considerable restlessness and perhaps some kind of impulsivity when the disorder "excites such a degree of anger as borders on insanity" (Crichton 1798, reprint p. 203). All symptoms observed by Crichton can be 
associated with ADHD. However, his descriptions do not entirely reflect the current concept of ADHD. He does not mention any symptoms of hyperactivity (Palmer and Finger 2001). It is possible that Crichton observed hyperactive or impulsive symptoms in his patients (Palmer and Finger 2001), but failed to recognize a correlation and decided not to specify them in this context. Another possibility is that he described the inattentive subtype of ADHD as suggested by Palmer and Finger (2001). His brief description is consistent with some of the symptoms of this ADHD subtype, but does not fully meet the criteria for a clinical diagnosis.

We do not know for certain whether the "morbid alteration" of attention described by Crichton is identical with the current concept of ADHD. Crichton's patients might have suffered from another disorder associated with attention problems, such as a metabolic dysfunction, epilepsy, or head injury. However, Crichton's descriptions provide some evidence for the existence of ADHD at the end of the eighteenth century.

\section{Fidgety Phil (Heinrich Hoffmann 1809-1894)}

In 1844, the German physician Heinrich Hoffmann created some illustrated children's stories including "Fidgety Phil" ("Zappelphilipp"), who is nowadays a popular allegory for children with ADHD. Hoffmann was born in Frankfurt/ Main in 1809. He studied medicine in Heidelberg, Halle, and Paris (Herzog et al. 1995). In 1835, he became a general practitioner and obstetrician in Frankfurt/Main (Herzog et al. 1995). In 1851, he was employed at the mental hospital of Frankfurt ("Anstalt für Irre und Epileptische") and became a successful psychiatrist (Herzog et al. 1995). Hoffmann rejected the common opinion of his time that psychiatric patients were obsessed or criminal, but rather regarded mental disorders as medical issues (Thome and Jacobs 2004). In 1861, he founded a new and very advanced hospital in Frankfurt. He was head of this institution until his retirement in 1888 (Herzog et al. 1995; Thome and Jacobs 2004) and was known for his revolutionary efforts to improve the conditions of psychiatric patients (Thome and Jacobs 2004).

In Germany, Hoffmann has become famous as the author of "Struwwelpeter", a storybook created in 1844 as a Christmas present for his 3-year-old son Carl Philipp (Hobrecker 1933). As Hoffmann detailed in his autobiography, he had several times previously pulled a piece of paper out of his notebook and had made little drawings to calm and amuse crying children, thus making possible an undisturbed medical examination (Hoffmann 1985, cited by Seidler 2004; Thome and Jacobs 2004). Hoffmann conceived "Struwwelpeter" for private use in order to delight his son. However, the publisher Löwenthal who had seen his manuscript convinced him to publish the colorful drawings (Thome and Jacobs 2004). In 1845, the first edition of the "Struwwelpeter", initially called "Cheerful Stories and Funny Pictures with 15 colored plates for children from 3 to 6 years" ("lustige Geschichten und drollige Bilder mit 15 kolorierten Tafeln für Kinder von 3 bis 6 Jahren”, Köpf 2006), was released with great success. The second edition followed a year later and Hoffmann added some stories, which included among others the story of Fidgety Phil (Hobrecker 1933). Hoffmann's Struwwelpeter was published in numerous editions and translated into several languages. The 400th edition was released in 1917 and the number of editions can no longer be counted these days (Herzog et al. 1995).

In the story of Fidgety Phil, Hoffmann illustrates a family conflict at dinner caused by the fidgety behavior of the son and culminating in his falling over together with the food on the table. This can be interpreted as an early case of ADHD. At the beginning of the story, the father asks "in earnest tone" (Hoffmann 1846, English edition): "Let me see if Philip can be a little gentleman; Let me see if he is able to sit still for once at table" (Hoffmann 1846, English edition). The initial statement suggests that the father had anticipated some misbehavior of his son at table, indicating that this was no singular or occasional event. It is a first hint at the presence of an underlying persistent disorder. The DSM-IV-TR currently postulates that, for a diagnosis of ADHD, the symptoms "have persisted for at least 6 months" (American Psychiatric Association 2000). Subsequently, Hoffmann describes symptoms of inattention and hyperactivity in Philipp. The boy's reaction to his father's admonition reads in the original German text as follows: "Doch der Philipp hörte nicht, was zu ihm der Vater spricht" (Hoffmann 1948), which, literally translated, means "but Philipp did not listen to what the father was saying to him". This behavior represents explicit symptoms of inattention. The DSM-IV-TR describes that the patient "often does not seem to listen when spoken to directly" and "often does not follow through on instructions (...) [what is] not due to oppositional behavior" (American Psychiatric Association 2000). Instead of following his father's request, Philipp "wriggled and giggled, and then, I declare, swung backward and forward and tilted his chair" (Hoffmann 1846, English edition). This description can be interpreted as symptoms of "motoric overactivity" (Burd and Kerbeshian 1988) and is close to the first symptom of hyperactivity characterized in the DSM-IV-TR: "often fidgets with hands or feet or squirms in seat" (American Psychiatric Association 2000). Hoffmann depicts Philipp's motor activity as being excessive enough that "his chair falls over quite. Philip screams with all his might, catches at the cloth, but then that makes 
matters worse again. Down upon the ground they fall, glasses, bread, knives forks and all" (Hoffmann 1846, English edition). The fact that Philipp's parents become very angry in the story (Hoffmann 1948) may hint at another DSM-IV-TR criterion, i.e. the behavior of children suffering from ADHD often causes conflicts and a "significant impairment in social (...) functioning" (American Psychiatric Association 2000).

Another story in Hoffmann's "Struwwelpeter" relevant to the present review is that of "Johnny Look-in-the-air", which was added in the 5th edition in 1847 (Seidler 2004). In this story, Hoffmann depicts a boy showing significant symptoms of inattention. Johnny was always "looking at the sky and the clouds that floated by" (Hoffmann 1846, English edition) and was therefore "often easily distracted by extraneous stimuli" (American Psychiatric Association 2000). Johnny's inattentiveness resulted in the collision with an approaching dog and climaxed in an accident as "Johnny watch'd the swallows" (Hoffmann 1846, English edition). He finally fell into a river.

Some authors are convinced that the stories of Johnny Look-in-the-air and Fidgety Phil are early descriptions of ADHD (Burd and Kerbeshian 1988; Köpf 2006; Thome and Jacobs 2004). However, Johnny Look-in-the-air's retropulsion of the head may also be interpreted as a description of a petit mal absence (Nissen 2005). Petit mal absences show a wide variety of mild to moderate motor accompaniment, and retropulsion of the head is quite common (retropulsive petit mal, Janz 1969). There are also critics who advance the view that Hoffmann's Fidgety Phil is simply an example of a naughty child (Seidler 2004). Seidler (2004) refers to the fact that the final version of the scene's pictures published in 1859 , which is the artwork still used in modern editions, differs from the original version of 1845 . Seidler (2004) sees in the slightly different gestures of the protagonists a completely different situation, namely an open conflict between a father and his naughty, misbehaving son. The father's initial admonition provokes the son's deliberate defiant behavior indicated by eye contact and the active gripping of the tablecloth by the son (Seidler 2004). Hoffmann's storybook was published at a time when educational warning stories were very popular (Herzog et al. 1995). Each of Hoffmann's stories demonstrates a child's misconduct leading to fatal consequences including death of the child. It is therefore possible that he wanted children to learn from his stories. Hoffmann's script is an illustrated children's book and he is therefore unlikely to have intended to address a broad medical readership and to describe a pathological condition. Since at his time the symptoms of inattention and hyperactivity were not established as a psychiatric disorder, Hoffmann may have presented observations of conspicuous behavior without considering describing a disorder. One cannot conclude whether or not Hoffmann's described a case of ADHD in the early nineteenth century, since the story of Fidgety Phil is too short and the depicted behavioral features are not sufficient to establish the diagnostic criteria of ADHD. Fidgety Phil has nevertheless become a commonly used allegory for ADHD.

\section{Defect of moral control (Sir George Frederic Still, 1868-1941)}

The Goulstonian Lectures of Sir George Frederic Still in 1902 are by many authors considered to be the scientific starting point of the history of ADHD (Barkley 2006a; Conners 2000; Palmer and Finger 2001; Rafalovich 2001; Rothenberger and Neumärker 2005). Still was a British pediatrician who was born in Highbury, London, in 1868. He became involved in research into childhood diseases and wrote several medical textbooks about his findings (Farrow 2006). The most widely known findings are his descriptions of "a form of chronic joint disease in children" (Still 1897), which today is called "Still's disease" (Farrow 2006). In 1906, Still became the first professor of pediatrics in England at King's College Hospital London (Farrow 2006). In 1933, he was president of the first international pediatric congress (Hamilton 1968). Still has therefore frequently been called "the father of British pediatrics" (Dunn 2006).

In his Goulstonian Lectures, a series of three lectures to the Royal College of Physicians of London "On Some Abnormal Psychical Conditions in Children" (Still 1902), Still discusses "the particular psychical conditions (...) which are concerned with an abnormal defect of moral control in children" (Still 1902, p. 1008). He defines moral control as "the control of action in conformity with the idea of the good of all" (Still 1902, p. 1008). Still states that "moral control (...) is dependent upon three psychical factors, a cognitive relation to environment, moral consciousness, and volition" (Still 1902, p. 1077). Since both "cognitive relation to environment", which implies a "capacity for reasoning comparison", and moral consciousness are intellectual capacities (Still 1902, p. 1008), Still states that defective moral control as a morbidity can often be observed in cases of mentally retarded children (Still 1902). However, "there are other cases which cannot be included in this category" (Still 1902, p. 1008) and which, as he points out, "in particular (...) call for careful observation" (Still 1902, p. 1008). They comprise the cases considered as historical descriptions of ADHD, i.e. children with a defect of moral control but without a "general impairment of intellect" (Still 1902, p. 1077). Still divides these cases in two further groups, children with a "morbid defect of moral control associated with 
physical disease" (Still 1902, p. 1077), such as a cerebral tumor, meningitis, epilepsy, head injury or typhoid fever, and children with a "defect of moral control as a morbid manifestation, without general impairment of intellect and without physical disease" (Still 1902, p. 1079). Some of the latter group, however, showed a "history of severe cerebral disturbance in early infancy" (Still 1902, p. 1081). This differentiation was the origin of later concepts of brain damage, minimal cerebral dysfunction, and hyperactivity as historical precursors to ADHD (Rothenberger and Neumärker 2005).

Still described 20 cases of children with a "defect of moral control as a morbid manifestation, without general impairment of intellect and without physical disease" (Still 1902, p. 1079). Interestingly, Still observed 15 cases of boys and five cases of girls. This is "a disproportion which [in Still's opinion] (...) is not altogether accidental" (Still 1902, p. 1080) and which is consistent with the commonly observed uneven male to female sex ratio of $3: 1$ in child and adolescent ADHD (Barkley 1990, cited by Palmer and Finger 2001). Most children for whom the first manifestation of the defect was determined showed symptoms before the age of 7 ( 7 out of 9 cases), which currently is a diagnostic criterion of DSM-IV-TR. Still furthermore recognized that a morbid manifestation of a child's moral control can be considered only when the child does not meet the standard for moral conduct at a certain age within a "range of variation which we arbitrarily recognize as normal" (Still 1902, p. 1009). The American Psychiatric Association also states that for a diagnosis of ADHD, symptoms have to be present "to a degree that is maladaptive and inconsistent with developmental level" (American Psychiatric Association 2000). Still argued that a "lack of moral control may be shown in many ways" (Still 1902, p. 1009). The symptoms listed are:

(1) passionateness; (2) spitefulness - cruelty; (3) jealousy; (4) lawlessness; (5) dishonesty; (6) wanton mischievousness - destructiveness; (7) shamelessness immodesty; (8) sexual immorality; and (9) viciousness. The keynote of these qualities is self-gratification, the immediate gratification of self without regard either to the good of others or to the larger and more remote good of self. (Still, 1902, p. 1009).

Although most of these symptoms are not directly associated with the current concept of ADHD, the keynote identified by Still fits an important finding of modern ADHD research. Delay of gratification appears to be "a major problem for children with ADHD" (Barkley 2006b) and reactions without regard to consequences, whether "to the good of others or (...) [the] good of self" (Still 1902, p. 1009), are strongly associated with impulsivity, a main symptom of ADHD. The most common symptom observed by Still in these cases was "an abnormal degree of passionateness" (Still 1902, p. 1009). Passionateness did not mean affection (Barkley 2006b), but some "impulsivity regarding some immediate goal" (Conners 2000, p. 176) and a kind of "quickness to display all emotion and especially those of frustration, anger, hostility, and aggression" (Barkley 2006b, p. 137), for example expressed "in outbursts of rage" (Still 1902, p. 1165). Similarly "jealousy" does, according to Still, not mean "the mere emotion but its uncontrolled expression" (Still 1902, p. 1009). Still attributes these symptoms to "a morbid failure to control (...) emotional activities" (Still 1902, p. 1165), which is due to an "exaggeration of excitability" (Still 1902, p. 1165). These descriptions are similar to the current concept of impulsivity. Although not explicitly mentioned in DSM-IV-TR, impulsivity as a main symptom of ADHD is often associated with a lack of emotional impulse control, a low frustration tolerance and some abrupt outbursts of rage (Barkley 2006b). Still describes some cases with signs of impulsivity,

for instance, the case of the boy, aged $11^{1 / 2}$ years (...): his mother stated that in the midst of playing quietly with other children he would suddenly seize two of them and bang their heads together, making them cry with pain and (...) he seems unable to resist it. (Still, 1902, p. 1165).

Still also mentions that many of his depicted cases showed "a quite abnormal incapacity for sustained attention. Both parents and school teachers have specially noted this feature in some of my cases as something unusual" (Still 1902, p. 1166). An attention deficit is a main symptom of ADHD and, according to the current DSM-IV-TR criteria, a child with ADHD "has difficulty sustaining attention in tasks or play activities" (American Psychiatric Association 2000). Difficulties at school are frequently observed in children with ADHD. In particular, the notion of children with a significant attention deficit, but "without general impairment of intellect" (Still 1902, p. 1079) fits modernday ADHD. Recent studies have shown that the IQ of children with ADHD is within the normal range (MTA Cooperative Group 1999; Schuck and Crinella 2005). Some of the cases cited by Still showed remarkable symptoms of inattention, for example,

the case of a boy with moral defect who would repeat the process of saying 'Good-night' several times before he was aware that he had done so; the same boy would often put his boot on the wrong foot apparently without noticing it. Another boy, aged six years, with marked moral defect was unable to keep his attention even to a game for more than a very short time, and, as might be expected, the failure of 
attention was very noticeable at school, with the result that in some cases the child was backward in school attainments, although in manner and ordinary conversation he appeared as bright and intelligent as any child could be (Still, 1902, p. 1166).

Many of Still's descriptions appear to indicate that children in the early twentieth century showed clear symptoms of ADHD. However, most of the symptoms listed by Still and described in his cases do not refer to ADHD. Still also reported children who "seemed to take a delight in tormenting the other children" (Still 1902, p. 1080), for example by throwing other children's toys in the fire and laughing at their grief. He furthermore described children who pathologically stole or lied with extraordinary insensitivity to any punishment, children who were aggressive and attacked strange children or threatened to hurt their mothers (Still 1902, p. 1081), "lawless" children with "a reckless disregard for command and authority" (Still 1902, p. 1009), children with "a complete lack of natural affection" (Still 1902, p. 1165) even to their parents, and children who showed cruelty to animals for example by attempting to put a cat in the fire (Still 1902, p. 1081) or by "cutting a rabbit alive (...) smothered in blood" (Still 1902, p. 1081).

Still's concept of a "defect of moral control" is not consistent with the concept of ADHD. Still did not predominantly refer to inattentive-impulsive children, but rather described several types of deviant behavior observed in children. "His description included the full range of externalizing behavior disorders" (Conners 2000), presumably many cases that would meet today's criteria for conduct disorder, oppositional defiant disorder, learning disabilities, or antisocial personality disorder (Palmer and Finger 2001; Barkley 2006b; Conners 2000). All these cases were combined in the concept of "defect of moral control". Among these cases, there were probably also some cases of ADHD such as the ones depicted above. Although the signs described by Still are consistent with some symptoms of ADHD, they are not sufficient for a clinical diagnosis of ADHD. Hyperactivity as a main symptom of ADHD is hinted at in one case, i.e. a girl who showed "marked fidgety, almost choreiform movements" (Still 1902, p. 1082). Still's work, nevertheless, “represents a break from the more general medical discussions of morality" (Rafalovich 2001) and his original notion of an impulsive syndrome which was distinguishable from general intellectual retardation and symptoms caused by physical diseases is pioneering (Conners 2000). He discusses both nature and nurture as possible factors underlying a lack of "moral control" and includes an elaborate description of family history in his cases. Still's Goulstonian lectures can be considered "the groundwork for a category of mental illness that is (...) specific to child deviance" (Rafalovich 2001) and a historically significant moment for child psychopathology in general (Barkley 2006b). Regardless of whether or not Still's descriptions include some cases of ADHD, his work is nevertheless important in the analysis of historical ideas concerning ADHD. Still's demonstration of a connection between brain damage and deviant behavior in children was highly influential regarding the further conceptualization of ADHD.

\section{Postencephalitic behavior disorder}

Some authors including Tredgold in 1908 gave an account of a correlation between early brain damage, for example caused by birth defect or perinatal anoxia, and subsequent behavior problems or learning difficulties (Tredgold 1908, cited by Rothenberger and Neumärker 2005). This was confirmed by the encephalitis lethargica epidemic, which spread around the world from 1917 to 1928 and affected approximately 20 million people (Conners 2000; Rafalovich 2001). The residual effects appeared as fatal as the encephalitis itself. The disease was thought to irreversibly damage the patients physically or mentally (Rafalovich 2001). Many of the affected children who survived the epidemic encephalitis, subsequently showed remarkably abnormal behavior. The residual effects were described as "postencephalitic behavior disorder" (Barkley 2006a; Rothenberger and Neumärker 2005). Frequently observed features included a significant change in personality, emotional instability, cognitive deficits, learning difficulties, sleep reversals, tics, depression, and poor motor control (Conners 2000; Kessler 1980; Rothenberger and Neumärker 2005). Children often became "hyperactive, distractible, irritable, antisocial, destructive, unruly, and unmanageable in school. They frequently disturbed the whole class and were regarded as quarrelsome and impulsive, often leaving the school building during class time without permission" (Ross and Ross 1976, p. 15). Bender (1942) described the postencephalitic behavior disorder to be "best understood as an organic driveness of brain stem origin. (...) This hyperkinesis leads the child to contact the environment continually, by touching, taking and destroying" (cited by Kessler 1980, p. 19). Many descriptions of children with this disorder include some characteristic symptoms of ADHD, and some behaviors of postencephalitic cases might also be attributed to ADHD. Most of the afflicted children, however, would not have met the current ADHD criteria. The postencephalitic behavior disorder aroused, nevertheless, a broad interest in hyperactivity in children, and the findings were influential 
for the further scientific development of the concept of ADHD (Rothenberger and Neumärker 2005). The era of the postencephalitic child pursued the course of Still and explained unconventional behavior of children physiologically and medicalized deviant child behavior. The assumption of a causal connection between brain damage and symptoms of hyperactivity and distractibility was important to the further conceptualization of ADHD (Rafalovich 2001; Rothenberger and Neumärker 2005).

\section{Hyperkinetic disease of infancy (Franz Kramer 1878-1967, and Hans Pollnow 1902-1943)}

In 1932, the German physicians Franz Kramer and Hans Pollnow reported "On a hyperkinetic disease of infancy" ("Über eine hyperkinetische Erkrankung im Kindesalter"). The most characteristic symptom of affected children was a marked motor restlessness (Kramer and Pollnow 1932, p. 1). The authors point out that the symptoms of this "hyperkinetic disease" had previously been observed and described by several authors, but the disorder had not been distinguished from other diseases with similar symptoms, such as the residual effects of the encephalitis lethargica epidemic. In their cases, the authors observed no bodily symptoms, sleep disturbances, or nocturnal agitation, which were specific to the postencephalitic behavior disorder (Kramer and Pollnow 1932, p. 39). In contrast to the postencephalitic motor drive, the restlessness observed in the cases of Kramer and Pollnow could be observed only by day (Kramer and Pollnow 1932, p. 39). The main symptoms of the "hyperkinetic disease" as described by Kramer and Pollnow are very similar to the current concept of ADHD.

According to Kramer and Pollnow, the most obvious symptom of children with hyperkinetic disease is a remarkable motor activity, which appears to be very urgent (Kramer and Pollnow 1932, p. 7). These children cannot stay still for a second, run up and down the room (Kramer and Pollnow 1932, p. 7), climb about preferring high furniture in particular (Kramer and Pollnow 1932, p. 10) and are displeased when deterred from acting out their motor impulses (Kramer and Pollnow 1932, p. 7). This description is very similar to the current characterization of hyperactivity, one of the main symptoms of ADHD. The American Psychiatric Association (2000) describes children with ADHD to leave their seats when "remaining seated is expected", to "run (...) about" and to be often "on the go" (American Psychiatric Association 2000). Excessive climbing is also an explicit hyperactive symptom of ADHD mentioned by the American Psychiatric Association (2000). The urgent character of the children's motor activity is reflected in the depiction of children with
ADHD as being "driven by a motor" (American Psychiatric Association 2000). Kramer and Pollnow furthermore consider the observed motor activity as being characterized by a conspicuous lack of purposefulness (Kramer and Pollnow 1932, p. 8). Children with hyperkinetic disease indiscriminately touch or move everything available without pursuing a goal (Kramer and Pollnow 1932, p. 7, p. 9). They often do not use objects according to their function, but regard them as stimuli inducing activity (Kramer and Pollnow 1932, p. 9). These children switch the light on and off, move chairs around the room, climb the table, the cupboard or the windowsill, jump around in their beds, turn keys in the keyhole, rip paper, go round in circles, throw objects out of the window, or beat their toys rhythmically on the floor without any purpose (Kramer and Pollnow 1932, p. 8 f.). This aimlessness of action exemplified by quickly changing activities is possibly due to a distinct distractibility by new and intensive stimuli, which is another symptom mentioned by Kramer and Pollnow. The children described by Kramer and Pollnow often cannot complete a set task or do not answer to questions (Kramer and Pollnow 1932, p. 13). They are unable to concentrate on difficult tasks (Kramer and Pollnow 1932, p. 17), which may cause learning deficits (Kramer and Pollnow 1932, p. 23) and make it difficult to assess their intellectual abilities (Kramer and Pollnow 1932, p. 18). These descriptions comply with the second main symptom of ADHD, i.e. inattention. The DSM-IV-TR depicts children with ADHD as being "easily distracted by extraneous stimuli" and as having "difficulty sustaining attention in tasks or play activities" (American Psychiatric Association 2000). Together with the fact that children with ADHD are known to have difficulties in planning and "organizing (...) activities" (American Psychiatric Association 2000), their playing can suggest a lack of purposefulness as described by Kramer and Pollnow. In addition, Kramer and Pollnow's observation of unresponsiveness in children with ADHD is reflected in the notion that a child with ADHD "often does not seem to listen when spoken to directly" (American Psychiatric Association 2000). Patients with ADHD typically have problems to concentrate and "to give close attention to details" (American Psychiatric Association 2000). It is also common for patients with inattention to leave work or activities uncompleted and to "fail (...) to finish (...) chores" (American Psychiatric Association 2000). This symptom is also described by Kramer and Pollnow as a further characteristic of the hyperkinetic child. According to these authors, hyperkinetic children show no perseverance in their activities, e.g. they play no game for more than a few minutes (Kramer and Pollnow 1932, p. 10). However, Kramer and Pollnow also noticed that the children were able to persevere at some activities of their interest for hours (Kramer and Pollnow 1932, 
p. 14). Both a lack of perseverance and the ability to concentrate on certain tasks can be observed in children with ADHD. Kramer and Pollnow describe furthermore that the children are unstable in their mood (Kramer and Pollnow 1932, p. 11). They observed an increased excitability, frequent fits of rage, and a tendency to become aggressive or to burst into tears for marginal reasons (Kramer and Pollnow 1932, p. 11). These are characteristic signs of impulsivity, and all main symptoms of ADHD are therefore present in the record of Kramer and Pollnow.

The description of the hyperkinetic disease also meets another criterion of ADHD. The American Psychiatric Association (2000) states that for a diagnosis of ADHD to be made, symptoms must cause "significant impairment in social, academic, or occupational functioning”. Kramer and Pollnow describe that hyperkinetic children are often disobedient (Kramer and Pollnow 1932, p. 13) and cause severe educational problems (Kramer and Pollnow 1932, p. 14). At school, they may cause confusion or disturb the class (Kramer and Pollnow 1932, p. 14). They often have difficulty playing harmoniously with other children and are generally unpopular among peers (Kramer and Pollnow 1932, p. 11). As mentioned previously, the presence of symptoms before the age of seven is an additional important diagnostic criterion in the DSM-IV-TR (American Psychiatric Association 2000). This criterion is also met by the cases of Kramer and Pollnow, since they reported an age of onset of the hyperkinetic disease as early as three or 4 years and a peak at the age of six. In many cases of Kramer and Pollnow, the abnormal behavior occurred following a feverish disease or epileptic convulsion (Kramer and Pollnow 1932, p. 23), which suggests an organic cause (Kramer and Pollnow 1932, p. 35). Kramer and Pollnow describe that the characteristics of the disorder, especially the motor restlessness, decline in intensity by the age of seven, and in most cases, the children recover in the subsequent years (Kramer and Pollnow 1932, p. 23), so that Kramer and Pollnow considered the disorder a "hyperkinesis of childhood" (Kramer and Pollnow 1932, p. 4). Although more than $50 \%$ of children with ADHD retain symptoms into adulthood (Barkley et al. 2002), the signs of hyperactivity decline with age in most cases of ADHD (Davidson 2008). Since Kramer and Pollnow considered abnormal motor activity as the most characteristic symptom of the disorder, they possibly regarded affected children as recovered when, regardless of other symptoms, this sign receded. However, Kramer and Pollnow recognized that the disorder can have implications into adulthood (Rothenberger and Neumärker 2005, p. 167).

In summary, the descriptions of Kramer and Pollnow "on a hyperkinetic disease of infancy" meet all three main symptoms of ADHD and two additional DSM-IV-TR criteria. In particular, their description of motor symptoms is highly consistent with the current classification systems (Rothenberger and Neumärker 2005). The introductory remark of Kramer and Pollnow that the pathological manifestation of the disorder had been known previously, but had not been recognized as a distinct disorder which had to be differentiated from other disorders with similar symptoms, is consistent with the historical literature. In summary, Kramer and Pollnow established a concept of the hyperkinetic disease that closely resembles the current concept of ADHD.

\section{The first treatment of hyperactivity (Charles Bradley 1902-1979)}

In 1937, Charles Bradley reported a positive effect of stimulant medication in children with various behavior disorders (Bradley 1937). Bradley was medical director of the Emma Pendleton Bradley Home, today called Bradley Hospital, in East Providence, Rhode Island, which was founded by his great-uncle George Bradley (Brown 1998) to treat neurologically impaired children (Conners 2000). Apart from children with definite neurological disorders or residual effects of encephalitis (Conners 2000), there where children hospitalized with "emotional problems" and major difficulties in learning and behavior. Some of these children would possibly be diagnosed with ADHD today (Gross 1995). Bradley's discovery of the improvement by stimulants of the behavior of children was based on a chance finding during his neurological examinations (Gross 1995). Bradley performed pneumoencephalograms in order to examine structural brain abnormalities (Rothenberger and Neumärker 2005). This usually caused severe headaches, which were supposed to be the result of a significant loss of spinal fluid. Bradley attempted to treat the headaches by stimulating the choroid plexus with benzedrine which was "the most potent stimulant available at the time" (Gross 1995). However, benzedrine had a negligible effect on the headaches, but caused a striking improvement in behavior and school performance in some of the children (Brown 1998; Gross 1995). Bradley subsequently started a systematic trial in 30 children of his hospital and observed remarkable alterations in behavior. "The most spectacular change in behavior brought about by the use of benzedrine was the remarkably improved school performance of approximately half the children" (Bradley 1937, p. 582). The children "were more interested in their work and performed it more quickly and accurately" (Gross 1995). In addition, some decrease in motor activity was usually noted in the children who also "became emotionally subdued without, however, losing interest in their surroundings" (Bradley 1937, p. 580). Bradley was surprised at this effect. "It appears paradoxical that a drug known to be a 
stimulant should produce subdued behavior in half of the children. It should be borne in mind, however, that portions of the higher levels of the central nervous system have inhibition as their function, and that stimulation of these portions might indeed produce the clinical picture of reduced activity through increased voluntary control" (Bradley 1937, p. 582). He later identified children who were most likely to benefit from benzedrine treatment as "characterized by short attention span, dyscalculia, mood lability, hyperactivity, impulsiveness, and poor memory" (Conners 2000). These features are nowadays associated with ADHD. Bradley's observations of stimulant effects in hyperactive children were revolutionary (Gross 1995) and are considered important discoveries in psychiatric treatment (Brown 1998).

\section{Methylphenidate (Leandro Panizzon)}

Although Bradley and his colleagues published their pioneering discovery in prominent journals (Brown 1998), their reports had almost no influence on research and practice for at least 25 years (Brown 1998; Conners 2000). This was possibly due to the wide influence of psychoanalysis at that time (Rothenberger and Neumärker 2005) and the assumption that behavioral disorders have no biological basis and require psychological interventions (Brown 1998). However, further investigations into this issue, for example by Laufer et al. (1957), produced growing interest in stimulant treatment of hyperkinetic children (Rothenberger and Neumärker 2005). At present, stimulant medication is the most frequently used treatment of children with ADHD (Wender 2000/2002). Benzedrine was the first stimulant drug administered to hyperactive children and is no longer in use. Methylphenidate is nowadays considered as drug of first choice (Leonard et al. 2004; Morton and Stockton 2000). The compound was first synthesized in 1944 by Leandro Panizzon and marketed as "Ritalin" by Ciba-Geigy Pharmaceutical Company in 1954 (Morton and Stockton 2000; Rothenberger and Neumärker 2005). The name "Ritalin" derives from the first name of Panizzon's wife, i.e. Marguerite or "Rita" (Rothenberger and Neumärker 2005). Methylphenidate is "a piperazinesubstituted phenylisopropylamine that is traditionally related to amphetamine" (Leonard et al. 2004, p. 151) and was initially used in the treatment of "a number of indications such as chronic fatigue, lethargy, depressive states, disturbed senile behavior, psychosis associated with depression and narcolepsy" (Leonard et al. 2004, p. 151). "However, its most impressive effect has been the reduction of symptoms seen in ADHD" (Morton and Stockton 2000, p. 159). Methylphenidate is regarded by now as the most effective psychostimulant and is the most frequently prescribed drug in the treatment of ADHD (Döpfner et al. 2000).

\section{Minimal brain damage}

The scientific history of hyperactivity was characterized by reports of brain damage in children presenting with abnormal behavior (Ross and Ross 1976). Following the lectures of Sir George Frederic Still in 1902, the assumptions of Tredgold in 1908, and the reports of the epidemic encephalitis from 1917 to 1928, several cases of children with behavior disorders were depicted who suffered from "gross lesions of the brain and a variety of acute diseases, conditions, and injuries that presumably had resulted in brain damage" (Ross and Ross 1976, p. 15). This indicated the growing notion that brain damage was the cause of hyperactive behavior (Ross and Ross 1976). Further research in the 1930s and 1940s supported the idea of a causal connection between brain damage and deviant behavior (Ross and Ross 1976). Children with a history of head injury were found to develop behavior disorders similar to the postencephalitic behavior disorder, while studies of birth trauma discovered a causative link between birth injury and mental retardation in children (Kessler 1980). Infections, lead toxicity, and epilepsy were also found to be associated with various cognitive and behavioral problems (Barkley 2006a). In the 1930s, several researchers found a striking similarity in behavior between hyperactive children and monkeys with a frontal lobe ablation (Barkley 2006a; Rothenberger and Neumärker 2005) and "experiences with brain-injured soldiers in particular have taught us that many a symptom considered psychogenic may be due to an organic cause" (Goldstein 1942, cited by Kessler 1980, p. 22). Rosenfeld and Bradley (1948) gave an account of typical behavior sequelae in children who suffered asphyxiant illness in infancy. They reported,

a fairly uniform overt behavior pattern in maladjusted children who have experienced asphyxiant illness in infancy. Six cardinal behavior characteristics make up this syndrome and may be listed as follows: 1 . Unpredictable variability in mood; 2. Hypermotility; 3. Impulsiveness; 4. Short attention span; 5. Fluctuant ability to recall material previously learned; and 6 . Conspicuous difficulty with arithmetic in school. (p. 74)

The notion of a physiological explanation of behavior disorders was remarkable (Rothenberger and Neumärker 2005). This led to the concept of "brain damage" (Kessler 1980) and the idea that hyperactivity in children may be caused by damage to the brain (Barkley 2006a). The new 
concept of "minimal brain damage" (Kessler 1980) was based on several considerations. First, Tredgold had stated that mild forms of brain damage in infancy, although unnoticed at the time, could lead to behavioral sequelae, which became first apparent at school (Ross and Ross 1976). Second, possible variations of brain damage in extent, locus, or type of lesion were discussed (Kessler 1976). Third, the concept of "a continuum of cerebral damage ranging from severe abnormalities, such as cerebral palsy and mental deficiency, to minimal damage" was introduced by Knobloch and Pasamanick (1959, p. 1384).

This new concept was characterized by the assumption that minimal damage to the brain, even when it cannot be demonstrated objectively, causes hyperactive behavior (Barkley 2006a; Ross and Ross 1976) and, in turn, "that even when brain damage could not be demonstrated it could be presumed to be present" (Ross and Ross 1976, p. 16). Under the influence of the work of Strauss and Lehtinen (1947) and Strauss and Kephart (1955), it became general practice to infer brain damage solely from behavioral signs without any neurological evidence of damage (Barkley 2006a; Ross and Ross 1976). In brain-injured and non-brain-injured mentally retarded children, Strauss and his colleagues identified a number of behavior patterns, on the basis of which they could distinguish these two groups (Ross and Ross 1976). In particular, they considered the symptom of hyperactivity as a sufficient diagnostic sign of underlying brain damage (Ross and Ross 1976). Minimal brain damage was therefore supposed to be clearly associated with a specific syndrome (Conners 2000). Most symptoms described in this context meet the current DSMIV-TR criteria, and the concept of minimal brain damage can be regarded as historical antecedent to ADHD. Laufer et al. (1957) describe the following characteristics of the syndrome:

It has long been recognized and accepted that a persistent disturbance of behavior of a characteristic kind may be noted after severe head injury, epidemic encephalitis and communicable disease encephalopathies, such as measles, in children. It has often been observed that a behavior pattern of a similar nature may be found in children who present no clear-cut history of any of the classical causes mentioned. This pattern will henceforth be referred to as hyperkinetic impulse disorder. In brief summary, hyperactivity is the most striking item. This may be noted from early infancy on or not become prominent until five or six years of age. There are also a short attention span and poor powers of concentration, which are particularly noticeable under school conditions. Variability also is frequent, with the child being described as quite unpredictable and with wide fluctuations in performance. The child is impulsive and does things "on the spur of the moment," without apparent premeditation. Outstandingly also these children seem unable to tolerate any delay in gratification of their needs and demands. They are irritable and explosive, with low frustration tolerance. (Laufer et al. 1957)

\section{Minimal brain dysfunction}

The hypothesis that minimal brain damage may lead to behavior disorders became well established. In the 1960s, however, many critics emerged who criticized the tests commonly used in the assessment of brain damage (Herbert 1964) and challenged the argument that every child presenting with abnormal behavior was to have minimal brain damage, even if this could neurologically not be demonstrated (Birch 1964; Rapin 1964, cited by Rothenberger and Neumärker 2005). Laufer et al. (1957) regarded it as a problem that there were "children who present the hyperkinetic impulse disorder without having any of the classic etiologic traumatic or infectious factors in their historical backgrounds" (Laufer et al. 1957). In their study, they found that "children with the hyperkinetic impulse disorder, regardless of whether or not their history contains clear-cut evidence of any agent causing injury to the central nervous system" (Laufer et al. 1957, p. 42) had a lower threshold for clinical responses in EEG to the administration of metrazol than children without the hyperkinetic syndrome. Following the administration of amphetamines, however, the threshold was similar to that of children without evidence of the syndrome (Laufer et al. 1957). Laufer and his colleagues supposed a dysfunction of the diencephalon to be the cause of the hyperkinetic syndrome (Laufer et al. 1957). Their results suggested a functional disturbance rather than damage to the brain as the cause of the characteristic syndrome (Conners 2000). In 1963, the Oxford International Study Group of Child Neurology (Bax and MacKeith 1963) held a conference and stated that brain damage should not be inferred from problematic behavior signs alone.

It became clear that this term has, for most people, the anatomical and aetiological implications that there has been an episode of injury and that this has produced anatomical change. Yet closer examination makes it clear that evidence of anatomical damage is usually absent, that evidence or history of an injuring process is often absent, and that disorder of function is the evidence used for applying the diagnostic label of "minimal brain damage" (Bax and MacKeith, 1963, unpaginated foreword, cited by Conners, 2000). 
The Oxford International Study Group of Child Neurology therefore advocated a shift in terminology by replacing the term "minimal brain damage" by "minimal brain dysfunction" (Ross and Ross 1976; Rothenberger and Neumärker 2005). They furthermore recommended that any effort should be undertaken to classify the heterogeneous group of children subsumed under the concept of minimal brain dysfunction into smaller and more homogenous subgroups (Ross and Ross 1976). Another conference held in 1963 by the National Institute of Neurological Diseases and Blindness (Conners 2000; Kessler 1980) assigned a national task force to work on terminology and identification of minimal brain dysfunction (Rie 1980). The national task force formulated the following official definition (Clements 1966):

The term minimal brain dysfunction refers to children of near average, average or above average general intelligence with certain learning or behavioural disabilities ranging from mild to severe, which are associated with deviations of function of the central nervous system. These deviations may manifest themselves by various combinations of impairment in perception, conceptualisation, language, memory and control of attention, impulse or motor function. (pp. 9 f.)

With regard to the etiology of the disorder, the concept of minimal brain dysfunction emphasized neurological factors including prenatal or perinatal "cerebral hypoxic lesions" (Towbin 1971) rather than environmental or social factors, such as parents and family, which were proposed by psychoanalysts (Barkley 2006a, Clements and Peters 1962). Since the definition of minimal brain dysfunction by Clements (1966) separates the symptoms "[impairment in] control of attention, impulse and motor function" (Clements 1966, p. 10) by the conjunction "and" from other "various combinations of impairment" (Clements 1966, pp. 9 f.), these three symptoms can be seen as "the central or defining criterion for MBD [minimal brain dysfunction]" (Conners 2000, p. 182). The concept of the three main symptoms of inattention, impulsivity, and hyperactivity characterizing ADHD was therefore established with the definition of minimal brain dysfunction. The assignment of children with minimal brain dysfunction to the normal range of intelligence and therefore the differentiation from "the brain-damaged mentally subnormal groups" (Clements 1966, p. 9) were important regarding the further conceptualization of ADHD.

\section{Hyperkinetic reaction of childhood (1968, second edition of the diagnostic and statistical manual of mental disorders: DSM-II)}

"The original concept of MBD (...) was not intended as a final statement on the subject" (Clements and Peters 1973 cited by Rie 1980). Although this concept persisted until the 1980s (Barkley 2006a), its decline already began in the 1960s when severe critiques arose (Rothenberger and Neumärker 2005). The presence of neurodevelopmental abnormalities was argued to be non-specific and also common in other psychiatric disorders (Schaffe et al. et al. 1985, cited by Conners 2000). It was found that many cases of known brain damage or dysfunction did not show hyperactivity or other symptoms postulated by the concept of minimal brain damage or dysfunction (Birch 1964, cited by Conners 2000). Minimal brain dysfunction was criticized as too general and heterogeneous and was later to be replaced by multiple more specific and descriptive labels such as "hyperactivity", "learning disability", "dyslexia" or "language disorders" (Barkley 2006a; Rothenberger and Neumärker 2005). Rie (1980) argued that the definition of minimal brain dysfunction was "more speculative than definitive", had no solid empirical basis, and lacked evidence. Further efforts to define the disorder were therefore based on objective observations of children's deficits, "rather than on some underlying unobservable etiological mechanism in the brain" (Barkley 2006a, p. 8). In this context, "hyperactivity [was] the most striking item" as was already stated in 1957 by Laufer, Denhoff and Solomons. Their idea of a "hyperkinetic impulse disorder" (Laufer et al. 1957) was continued in the 1960s, and the concept of a hyperactivity syndrome was generated (Barkley 2006a). Hyperactivity was recognized to be "a behavioral syndrome that could arise from organic pathology, but could also occur in its absence. Even so, it would continue to be viewed as the result of some biological difficulty, rather than due solely to environmental causes" (Barkley 2006a, p. 8). In 1968, a definition of the concept of hyperactivity was incorporated in the official diagnostic nomenclature, i.e. the second edition of the Diagnostic and Statistical Manual of Mental Disorders (DSM-II) (Barkley 2006a; Volkmar 2003). This concept was labeled "Hyperkinetic Reaction of Childhood" and defined with two sentences: "The disorder is characterized by overactivity, restlessness, distractibility, and short attention span, especially in young children; the behavior usually diminishes by adolescence" (American Psychiatric Association 1968, p. 50, cited by Barkley 2006a, p. 9). 
Attention deficit disorder: with and without hyperactivity (1980, third edition of the diagnostic and statistical manual of mental disorders: DSM-III)

In the 1970s, the predominant focus on hyperactivity was shifted toward an emphasis on the attention deficit in affected children (Rothenberger and Neumärker 2005). In a paper addressed to the Canadian Psychological Association, Douglas (1972) argued that deficits in sustained attention and impulse control were more significant features of the disorder than hyperactivity (cited by Barkley 2006a; Douglas 1984; Rothenberger and Neumärker 2005). In addition, these symptoms were the ones showing the best response to stimulant treatment (Douglas 1972, cited by Rothenberger and Neumärker 2005). Douglas' paper was very influential at the time and provoked further research on this issue and finally initiated a complete change in the conceptualization of the Hyperkinetic Reaction of Childhood (Barkley 2006a). "In 1980, the importance of attentional problems in the syndrome was recognized — and perhaps exaggerated - by the adoption of a new diagnostic label" (Douglas 1984). With the publication of DSM-III in 1980, the American Psychiatric Association renamed the disorder "Attention Deficit Disorder (ADD) (with or without hyperactivity)" (Barkley 2006a; Rothenberger and Neumärker 2005). DSM-III took the position that hyperactivity was no longer an essential diagnostic criterion for the disorder and that the syndrome occurred in two types "with or without hyperactivity" (Conners 2000). Deficits in attention and impulse control were, however, considered significant symptoms in establishing a diagnosis (Barkley 2006a). In this respect, DSM-III departed from the "International Classification of Diseases (ICD-9)" by the World Health Organization, which continued to focus on hyperactivity as indicator of the disorder. DSM-III developed three separate symptom lists for inattention, impulsivity, and hyperactivity, which were far more specific than previous ones (Barkley 2006a). In addition, DSM-III introduced "an explicit numerical cutoff score for symptoms, specific guidelines for age of onset and duration of symptoms, and the requirement of exclusion of other childhood psychiatric conditions" (Barkley 2006a, pp. 19 f.)

\section{Attention deficit hyperactivity disorder (1987, revision of the third edition of the diagnostic and statistical manual of mental disorders: DSM-III-R)}

The discussion regarding the importance of certain symptoms continued, and the creation of subtypes of ADD on the basis of the presence or absence of hyperactivity was discussed controversially (Barkley 2006a). When the concept of ADD was formulated, "little, if any empirical research on this issue existed" (Barkley 2006a). At that time, it was not evident if the attention deficit of the subtype of ADD without hyperactivity was qualitatively similar to that of the subtype with hyperactivity, or if the two types had to be considered as two separate psychiatric disorders (Barkley 2006a). In order to further improve the criteria, in particular with respect to empirical validation, the revision of the third edition of the Diagnostic and Statistical Manual of Mental Disorders (DSM-III-R) in 1987 removed the concept of two subtypes and renamed the disorder "Attention deficit-Hyperactivity Disorder (ADHD)". The symptoms of inattention, impulsivity, and hyperactivity were combined into a single list of symptoms with a single cutoff score. The symptoms were empirically derived by rating scales and a field trial (Barkley 2006a; Conners 2000). The subtype "ADD without hyperactivity" was removed and assigned to a residual category named "undifferentiated ADD" (Rothenberger and Neumärker 2005).

\section{Attention deficit hyperactivity disorder (1994, fourth edition of the diagnostic and statistical manual of mental disorders: DSM-IV)}

In addition to the reorganization of the concept of ADD, several studies examined the existence of subtypes of ADD at the end of the 1980s (Barkley 2006a). It was found that children with ADD without hyperactivity differed from children with ADD with hyperactivity in that they were "more daydreamy, hypoactive, lethargic, and disabled in academic achievement, but as substantially less aggressive and less rejected by their peers" (Barkley 2006a, p. 21). In addition, some doubts arose as to the central role of a deficit in attention in so-called ADHD. The view emerged that motivational factors and deficits in reinforcement mechanisms were of major importance (Barkley 2006a). Historical interpretations of brain damage or dysfunction were supported by the evidence of structural abnormalities in the brain of children with ADHD as shown with new neuroimaging techniques. Up until the end of the 1990s, most studies "have implicated the prefrontal-striatal network as being smaller in children with ADHD" (Barkley 2006a). Further research found a genetic component of the disorder (Biederman et al. 1990, cited by Barkley 2006a). It was finally recognized in the 1990s that ADHD was not exclusively a childhood disorder, which disappeared with age as was previously thought (Barkley 2006a), but rather a chronic, persistent disorder remaining into adulthood in many cases (Döpfner et al. 2000). Before the fourth edition of the Diagnostic and Statistical Manual of Mental Disorders (DSM-IV) was 
outlined in 1994, another large field trial was conducted (Lahey et al. 1994). Three subtypes of ADHD were identified on the basis of structured diagnostic interviews of multiple informants and of validation diagnoses. The previously heterogeneous category of ADHD according to DSM-III-R was consequently subdivided into three subtypes (Lahey et al. 1994), i.e. a predominantly inattentive type, a predominantly hyperactive-impulsive type, and a combined type with symptoms of both dimensions (American Psychiatric Association 1994). By using this categorization, the concept of the two separate dimensions of attention deficit and hyperactivity-impulsivity was reverted (Conners 2000) and the possibility of a diagnosis of a purely inattentive form of the disorder was reintroduced (Barkley 2006a). The American Psychiatric Association accredited the diagnosis of ADHD in adulthood by including examples of workplace difficulties in the depiction of symptoms. "Based on a much larger field trial than any of their predecessors, the DSM-IV criteria for ADHD are the most empirically based in the history of this disorder" (Barkley 2006a).

\section{Attention deficit hyperactivity disorder (2000, text revision of the fourth edition of the diagnostic and statistical manual of mental disorders: DSM-IV-TR)}

In order to bridge the span between DSM-IV and DSM-V, a text revision of the fourth edition of the DSM was undertaken in 2000 (American Psychiatric Association 2000). The main goals were to "maintain the currency of the DSM-IV text" (American Psychiatric Association 2009) and to correct any errors identified in the DSM-IV text. "Thus, most of the major changes in DSM-IV-TR were confined to the descriptive text" (American Psychiatric Association 2009). The definition of ADHD has therefore not been changed. A new edition of the DSM is in progress. Critics have called for a validation of ADHD in adults (Fischer and Barkley 2007; McGough and Barkley 2004). Since the DSM-IV field trials for ADHD included only children and adolescents up to the age of 17 (Lahey et al. 1994), the utility of the DSM-IV criteria in the diagnosis of adults with ADHD has been challenged (Fischer and Barkley 2007). The publication of the fifth edition of the DSM is not scheduled until 2012.

DSM-IV and ICD-10 have adopted almost identical criteria for the identification of inattentive, hyperactive, and impulsive symptoms. However, significant differences are still evident in the number of criteria in each domain required for a diagnosis, the importance of inattention and the handling of comorbidity. In comparison with DSM-IV, ICD-10 is more demanding about cross-situational pervasiveness and requires that all necessary criteria be present, both at home and at school or other situations.

\section{Future directions}

The development of the international classification systems appears to reflect a growing consensus regarding the clinical entity of ADHD. Evidence has been presented (Faraone 2005) to show that ADHD meets the criteria established by Robins and Guze (1970) for the validation of psychiatric diagnoses. Patients with ADHD show a characteristic pattern of hyperactivity, inattention, and impulsivity that lead to adverse outcomes. ADHD can be distinguished from other psychiatric disorders including those with which it is frequently comorbid. Longitudinal studies have demonstrated that ADHD is invariably chronic and not an episodic disorder. Twin studies show that ADHD is a highly heritable disorder. Molecular genetic studies have found genes that explain some of the disorder's genetic transmission. Neuroimaging studies show that ADHD patients have abnormalities in frontal-subcorticalcerebellar systems involved in the regulation of attention, motor behavior, and inhibition. Many individuals with ADHD show a therapeutic response to medications that block the dopamine or noradrenaline transporter. This evidence as reviewed by Faraone (2005) supports the hypothesis of ADHD being a clinical entity and fulfilling the Robins and Guze (1970) validity criteria.

However, there has been considerable debate about this issue. Critics have described ADHD as a diagnosis used to label difficult children who are not ill but whose behavior is at the extreme end of the normal range. Concerns have been raised that "ADHD is not a disease per se but rather a group of symptoms representing a final common behavioral pathway for a gamut of emotional, psychological, and/or learning problems" (Furman 2005). Most of the research studies available rely on clinically referred cases, i.e. severely ill or narrowly diagnosed patients. The generalization of the research findings to non-referred cases in the community is therefore not necessarily valid.

In summary, the cardinal ADHD symptoms of inattention, hyperactivity, and impulsivity are not unique to ADHD. In addition, there is a remarkable overlap of these ADHD symptoms with those of comorbid mental health conditions or learning problems. A consistent genetic marker has not been found, and neuroimaging studies have been unable to identify a distinctive etiology for ADHD. The lack of evidence of a unique genetic, biological, or neurological pathology hinders the general acceptance of ADHD as a neurobehavioral disease entity. In addition, the ratings of school children with ADHD by parents and teachers are frequently discrepant and do not appear to 
provide an objective diagnostic basis. The issue of the clinical entity of ADHD remains therefore an open question and requires further investigation.

Open Access This article is distributed under the terms of the Creative Commons Attribution Noncommercial License which permits any noncommercial use, distribution, and reproduction in any medium, provided the original author(s) and source are credited.

\section{References}

American Psychiatric Association (1968) Diagnostic and statistical manual of mental disorders (DSM-II), 2nd edn. American Psychiatric Association, Washington DC

American Psychiatric Association (1980) Diagnostic and statistical manual of mental disorders (DSM-III), 3rd edn. American Psychiatric Association, Washington DC

American Psychiatric Association (1987) Diagnostic and statistical manual of mental disorders (DSM-III-R), 3rd edn rev. American Psychiatric Association, Washington DC

American Psychiatric Association (1994) Diagnostic and statistical manual of mental disorders (DSM-IV), 4th edn. American Psychiatric Association, Washington DC

American Psychiatric Association (2000) Diagnostic and statistical manual of mental disorders (DSM-II), 4th edn Text revision. American Psychiatric Association, Washington DC

American Psychiatric Association (2009) http://www.psych.org/ mainmenu/research/dsmiv/dsmivtr.aspx

Arolt V (2008) Aufmerksamkeitsdefizit-/Hyperaktivitätsstörung. Wachsendes Wissen erfordert neue therapeutische Möglichkeiten. Nervenarzt 79:769-770

Barkley RA (2006a) Attention-deficit hyperactivity disorder. A Handbook for Diagnosis and Treatment, Guilford, New York

Barkley RA (2006b) The relevance of the Still lectures to attentiondeficit/hyperactivity disorder: a commentary. J Atten Disord 10:137-140

Barkley RA, Fischer M, Smallish L, Fletcher K (2002) The persistence of attention-deficit/hyperactivity disorder into young adulthood as a function of reporting source and definition of disorder. J Abnorm Psychol 111:279-289

Bax M, MacKeith R (1963) Minimal cerebral dysfunction. Little Club Clinics in developmental medicine. Heineman, London

Bender L (1942) Postencephalitic behavior disorders in children. In: Neal JB (ed) Encephalitis: a clinical study. Grune \& Stratton, New York, pp 361-385

Biederman J, Faraone SV, Keenan K, Knee D, Tsuang MT (1990) Family-genetic and psychosocial risk factors in DSM-III attention deficit disorder. J Amer Acad Child Adolesc Psychiatry 29: 526-533

Birch HG (1964) Brain damage in children: the biological and social aspects. Williams \& Wilkens, Baltimore

Bradley C (1937) The behavior of children receiving benzedrine. Am J Psychiatry 94:577-585

Brown WA (1998) Charles Bradley, M.D., 1902-1979. Am J Psychiatry 155:968

Burd L, Kerbeshian J (1988) Historical roots of ADHD. J Am Acad Child Adolesc Psychiatry 27:262

Clements SD (1966) Minimal brain dysfunction in children: terminology and identification: phase one of a three-phase project. US Department of Health, Education and Welfare, Washington DC

Clements SD, Peters JE (1962) Minimal brain dysfunctions in the school-age child. Diagnosis and treatment. Arch Gen Psychiatry 6:185-197
Clements SD, Peters JE (1973) Psychoeducational programming for children with minimal brain dysfunctions. In: De la Cruz FF, Fox BH, Roberts RH (eds) Minimal brain dysfunction. New York Academy of Sciences, New York, pp 46-51

Conners CK (2000) Attention-deficit/hyperactivity disorder: historical development and overview. J Atten Disord 3:173-191

Crichton A (1798) An inquiry into the nature and origin of mental derangement: comprehending a concise system of the physiology and pathology of the human mind and a history of the passions and their effects. Cadell $\mathrm{T}$ Jr, Davies W, London [Reprint: Crichton A (2008) An inquiry into the nature and origin of mental derangement. On attention and its diseases. J Atten Disord 12:200-204]

Davidson MA (2008) ADHD in adults. A review of the literature. J Atten Disord 11:628-641

Döpfner M, Frölich J, Lehmkuhl G (2000) Hyperkinetische Störungen. In: Döpfner M, Lehmkuhl G, Peterman F (eds) Reihe Leitfaden Kinder- und Jugendpsychotherapie, Bd. 1. Hogrefe, Göttingen

Douglas VI (1972) Stop, look and listen: the problem of sustained attention and impulse control in hyperactive and normal children. Can J Behav Sci 4:259-282

Douglas VI (1984) Citation classic. Stop, look and listen: the problem of sustained attention and impulse control in hyperactive and normal children. Soc Behav Sci 44:16

Dunn PM (2006) Sir Frederic Still (1868-1941): the father of British paediatrics. Arch Dis Child Fetal Neonatal Ed 9:F308-F310

Faraone SV (2005) The scientific foundation for understanding attention deficit/hyperactivity disorder as a valid psychiatric disorder. Eur Child Adolesc Psychiatry 14:1-10

Farrow SJ (2006) Sir George Frederick Still (1868-1941). Rheumatology 45:777-778

Fischer M, Barkley RA (2007) The persistence of ADHD into adulthood: (once again) it depends on whom you ask. ADHD Rep 15:7-16

Furman L (2005) What is attention-deficit hyperactivity disorder (ADHD)? J Child Neurol 20:994-1002

Goldstein K (1942) After-effects of brain injuries in war. Grune and Stratton, New York

Gross MD (1995) Origin of stimulant use for treatment of attention deficit disorder [letter]. Am J Psychiatry 152:298-299

Hamilton EBD (1968) George Frederic Still. Ann Rheum Dis 45:1-5

Herbert M (1964) The concept and testing of brain damage in children-a review. J Child Psychol Psychiatry 5:197-217

Herzog GH, Herzog-Hoinkis M, Siefert H (1995) Heinrich Hoffmann. Leben und Werk in Texten und Bildern. Insel-Verlag, Frankfurt am Main/Leipzig

Hobrecker K (1933) Nachwort zu: Heinrich Hoffmann. Der Struwwelpeter. Insel-Verlag, Leipzig

Hoffmann H (1948) Der Struwwelpeter. Oder lustige Geschichten und drollige Bilder für Kinder von 3 bis 6 Jahren. Frankfurter Originalausgabe, Loewes, Stuttgart

Hoffmann H (1985) Lebenserinnerungen. In: Herzog CH, Siefert $\mathrm{H}$ (eds) Gesammelte Werke. Main, Frankfurt

Janz D (1969) Die Epilepsien. Thieme, Stuttgart

Kessler JW (1980) History of minimal brain dysfunctions. In: Rie HE, Rie ED (eds) Handbook of minimal brain dysfunctions: a critical view. Wiley, New York, pp 18-51

Knobloch H, Pasamanick B (1959) Syndrome of minimal cerebral damage in infancy. JAMA 170:1384-1387

Köpf G (2006) ICD-10 literarisch. Deutscher Universitäts-Verlag, Wiesbaden

Kramer F, Pollnow H (1932) Über eine hyperkinetische Erkrankung im Kindesalter. Aus der Psychiatrischen und Nerven-Klinik der Charité in Berlin (Direktor: Geh. Med.-Rat Prof. Dr. Bonhoeffer). Mschr Psychiat Neurol 82:21-40 [Reprint in Rothenberger 
A, Neumärker KJ (2005) Wissenschaftsgeschichte der ADHS. Kramer-Pollnow im Spiegel der Zeit. Steinkopff, Darmstadt]

Lahey BB, Applegate B, McBurnett K, Biederman J, Greenhill L, Hynd GW et al (1994) DSM-IV field trials for attention deficit hyperactivity disorder in children and adolescents. Am J Psychiatry 151:1673-1685

Laufer MW, Denhoff E, Solomons G (1957) Hyperkinetic impulse disorder in children's behavior problems. Psychosom Med 19:38-49

Leonard BE, McCartan D, White J, King DJ (2004) Methylphenidate: a review of its neuropharmacological, neuropsychological and adverse clinical effects. Hum Psychopharmacol Clin Exp 19:151-180

McGough JJ, Barkley RA (2004) Diagnostic controversies in adult attention deficit hyperactivity disorder. Am J Psychiatry 161:1948-1956

Morton WA, Stockton GG (2000) Methylphenidate abuse and psychiatric side effects. Prim Care Companion J Clin Psychiatry 2:159-164

MTA Cooperative Group (1999) A 14-month randomized clinical trial of treatment strategies for attention-deficit/hyperactivity disorder. Arch Gen Psychiatry 56:1073-1086

Nissen G (2005) Kulturgeschichte seelischer Störungen bei Kindern und Jugendlichen. Klett-Cotta, Stuttgart

Okie S (2006) ADHD in adults. N Engl J Med 354:2637-2641

Palmer E, Finger S (2001) An early description of ADHD (Inattentive Subtype): Dr Alexander Crichton and 'Mental Restlessness' (1798). Child Psychol Psychiatry Rev 6:66-73

Rafalovich A (2001) The conceptual history of attention deficit hyperactivity disorder: idiocy, imbecility, encephalitis and the child deviant, 1877-1929. Deviant Behav 22:93-115

Rapin I (1964) Brain damage in children. In: Brennemann J (ed) Practice of paediatrics, vol 4. MD Prior, Hagerstown

Rie HE (1980) Definition problems. In: Rie HE, Rie ED (eds) Handbook of minimal brain dysfunctions: a critical view. Wiley, New York, pp 18-51

Robins E, Guze SB (1970) Establishment of diagnostic validity in psychiatric illness: its application to schizophrenia. Am J Psychiatry 126:983-987
Rosenfeld GB, Bradley C (1948) Childhood behavior sequelae of asphyxia in infancy. Pediatrics 2:74-84

Ross DM, Ross SA (1976) Hyperactivity: research, theory and action. Wiley, New York

Rothenberger A, Neumärker KJ (2005) Wissenschaftsgeschichte der ADHS. Kramer-Pollnow im Spiegel der Zeit, Steinkopff, Darmstadt

Schuck SEB, Crinella FM (2005) Why children with ADHD do not have low IQs. J Learn Disabil 38:262-280

Seidler E (2004) "Zappelphilipp" und ADHS. Von der Unart zur Krankheit. Dtsch Arztebl 101:A239-A243

Still GF (1897) On a form of joint disease in children. Medico-Chir Trans 80:47-59

Still GF (1902) Some abnormal psychical conditions in children: the Goulstonian lectures. Lancet 1:1008-1012

Strauss AA, Kephart NC (1955) Psychopathology and education of the brain-injured child. Volume II. Progress in theory and clinic. Grune \& Stratton, New York

Strauss AA, Lehtinen LE (1947) Psychopathology and education of the brain-injured child. Grune \& Stratton, New York

Tansey EM (1984) The Life and Works of Sir Alexander Crichton, F.R.S. (1763-1856): a Scottish physician to the imperial Russian Court. Notes Rec R Soc Lond 38:241-259

Thome J, Jacobs K (2004) Attention deficit hyperactivity disorder (ADHD) in a 19th century children's book. Eur Psychiatry 19:303-306

Towbin A (1971) Organic causes of minimal brain dysfunction. Perinatal origin of minimal cerebral lesions. JAMA 217:1207-1214

Tredgold CH (1908) Mental deficiency (amentia), 1st edn. Wood, New York

Volkmar FR (2003) Changing perspectives on ADHD. Am J Psychiatry 160:1025-1027

Wender PH (2002) Aufmerksamkeits- und Aktivitätsstörungen bei Kindern, Jugendlichen und Erwachsenen. Ein Ratgeber für Betroffene und Helfer (F. Badura, Trans.) Kohlhammer, Stuttgart 